\title{
A QUALIDADE DE TRANSMISSÃO DA VOCALIZAÇÃO EM CÂMARAS NO SOLO DA ESPÉCIE LEPTODACTYLUS TROGLODYTES \\ (ANURA: LEPTODACTYLIDAE)
}

\author{
$\underline{\text { Juliane Santos da Silva }}{ }^{1}$; Flora Acuña Juncá ${ }^{2}$; \\ 1. Bolsista PROBIC/UEFS, Graduanda em Ciências Biológicas, Universidade Estadual de Feira de Santana, \\ e-mail: julisilvasantos22@outlook.com \\ 2. Orientadora Flora AcuñaJuncá, Departamento de Ciências Biológicas, Universidade Estadual de Feira de \\ Santana, e-mail:florajunc@gmail.com
}

PALAVRAS-CHAVE: anfíbios; bioacústica;vocalização.

\section{INTRODUÇÃO}

A comunicação se baseia no envio de uma informação de um emissor para um receptor e o veículo pelo qual essa informação é passada é chamado sinal (Simmons, 2003). A comunicação acústica é muito importante na reprodução dos anfíbios anuros, pois o macho emite o canto, a fêmea interpreta este sinal e usa suas características acústicas paraselecionar o parceiro sexual (Simmons, 2003). Neste contexto, estudos prévios têm mostrado que fêmeas, de várias espécies, exibem preferências por propriedades acústicas as quais há um alto gasto energético por parte do macho que vocaliza (Gerhardt\& Huber, 2002).

As propriedades espectrais dos cantos (frequência e amplitude) podem estar relacionadas à morfologia do macho. A frequiência dominante está relacionada à massa e ao tamanho das cordas vocais. Já as propriedades temporais, como o número de notas e a duração do canto, são influenciadas pelo comportamento e pela temperatura (Ryan, 1988). A transmissão do sinal acústico pode sofrer interferências; a degradação e atenuação são fatores responsáveis pela perda das características do sinal durante a transmissão do som através da atmosfera.

Os sinais acústicos evoluíram para comunicação a longas distâncias e esses sinais estão geralmente sujeitos a forte seleção natural imposta pelo ambiente, como presença de predadores e competidores (Ryan\&Kime, 2003). Interferências ambientais podem degradar o sinal destes animais, como a reverberação que causa principalmente redirecionamento das ondas sonoras a partir de folhas, galhos e outros componentes da vegetação. Algumas características acústicas podem minimizar essas interferências, por exemplo, os sinais sonoros de maior duração têm mais chances de se propagar com menor degradação (Wiley\& Richards, 1978). A frequência $(\mathrm{Hz})$ é outra característica que pode aumentar o alcance da transmissão. Os sinais emitidos em entre $1 \mathrm{e} 4 \mathrm{kHz}$ têm um maior alcance de transmissão do sinal na comunicação acústica independente do habitat,(Wiley\&Richards, 1978)

Algumas espécies como Leptodactylus troglodytes, podem vocalizar no interior de câmaras em solo úmido, perto de lagoas temporárias. Estas câmaras podem ser buracos formados por raízes de árvores ou arbustos, ou cavidades entre rochas ou entre rochas e solo. Estas câmaras além de proteção para acasalar com as fêmeas, podem também servir como um mecanismo de amplificação do som, promovendo uma propagação mais eficiente. Este trabalho visa investigar as características dos cantos emitidos pela 
espécie Leptodactylus troglodytes, bem como as alterações sofridas na estrutura dos cantos quando emitidos em câmaras de diferentes proporções.

\section{MATERIAL E MÉTODOS}

Para o experimentoforam utilizados os cantos de cinco indivíduos, previamente gravados, para a criação de um trecho em MP3 de dois minutos, utilizando o programa Raven Pró 1.3. Os animais encontravam-se vocalizando livres no momento da gravação e foram coletados após a mesma. Os cantos estão disponíveis na sonoteca da Divisão de Anfíbios e Répteis do Museu de Zoologia da UEFS sob números 100_193, 100_195, 100_196, 100_396, 100_401. Os indivíduos gravados estão depositados na Divisão de Anfíbios e Répteis, Museu de Zoologia da Universidade Estadual de Feira de Santana (MZFS3927, MZFS3928, MZFS3929, MZFS4324, MSFS4325).

Para verificar se a qualidade da câmara, em termos de volume, pode afetar a qualidade do sinal durante sua transmissão, realizamos um experimento no qual foram utilizados três recipientes cúbicos de diferentes volumes (três, cinco, e sete litros) e de seguintes dimensões: 3L (altura $18 \mathrm{~cm}$, largura $16 \mathrm{~cm}$ e comprimento $16 \mathrm{~cm}), 5 \mathrm{~L}(21 \mathrm{~cm}, 18 \mathrm{~cm}$ $18 \mathrm{~cm})$ e $7 \mathrm{~L}(32 \mathrm{~cm}, 21 \mathrm{~cm}, 21 \mathrm{~cm})$. Estes recipientes simularam as câmaras onde os indivíduos vocalizam na natureza. Para reprodução do trecho MP3 foi utilizado caixa de som portátil Speaker Ws-887. Para a gravação do som, foi usado microfone Sennheiser direcional, gravador Marantz PMD661. Para medir a amplitude do som no momento de reprodução, foi utilizado um decibelímetro Minipa MSL- $1351 \mathrm{C}$ antes de colocar a caixa acústica nas câmaras.

O experimento foi realizado no Museu de Zoologia da UEFS, em uma sala fechada, sem vento ou ruídos externos. A fita foi reproduzida, primeiramente com a caixa de som portátil dentro do recipiente de três litros e gravada a distâncias de um, dois, quatro e oito metros. A gravação foi repetida também nos recipientes de cinco e sete litros, nas mesmas distâncias. As amplitudes dos cantos no momento da gravação variaram entre 59 e $70 \mathrm{~dB}$.

Posteriormente os parâmetros acústicos das gravações foram analisados no programa Raven Pró 1.3. Os seguintes parâmetros acústicos foram considerados: duração do canto (s), o pico de frequência $(\mathrm{Hz})$ e o pico de amplitude $(\mathrm{dB})$. Para cada parâmetro, foi feita uma média dos 5 cantos emitidos em cada recipiente (3L, 5L e 7L) e a cada distância (1m, 2m, $4 \mathrm{~m}$ e $8 \mathrm{~m})$.

\section{RESULTADOS E DISCUSSÃO}

De maneira geral, ao longo da transmissão houve uma tendência no aumento da duração do canto, embora essas variações, com uma exceção, tenham sido relativamente baixas (Figura 1). Entretanto, estas variações na duração do canto foram mais baixas no recipiente de 3L ao longo da sua propagação, a exceção da distância de oito metros, que foi visivelmente muito mais alta que todas as outras distâncias (Figura 1). 


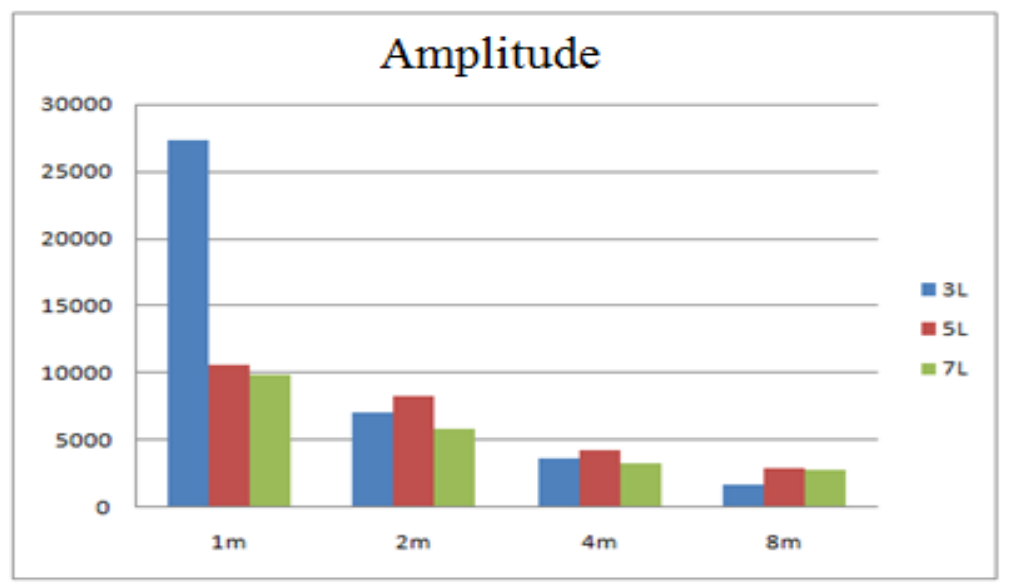

Figura 01. Variação da duração do canto (s) de Leptodactylus troglodytes, em diferentes distâncias ao longo da sua transmissão e emitidos em recipientes de diferentes volumes.

A amplitude do som diminuiu ao longo das distâncias, nos três recipientes (Figura 2). Nota-se, entretanto que a um metro, no recipiente de três litros, houve maior pico de amplitude registrado e consideravelmente maior que todos os outros.

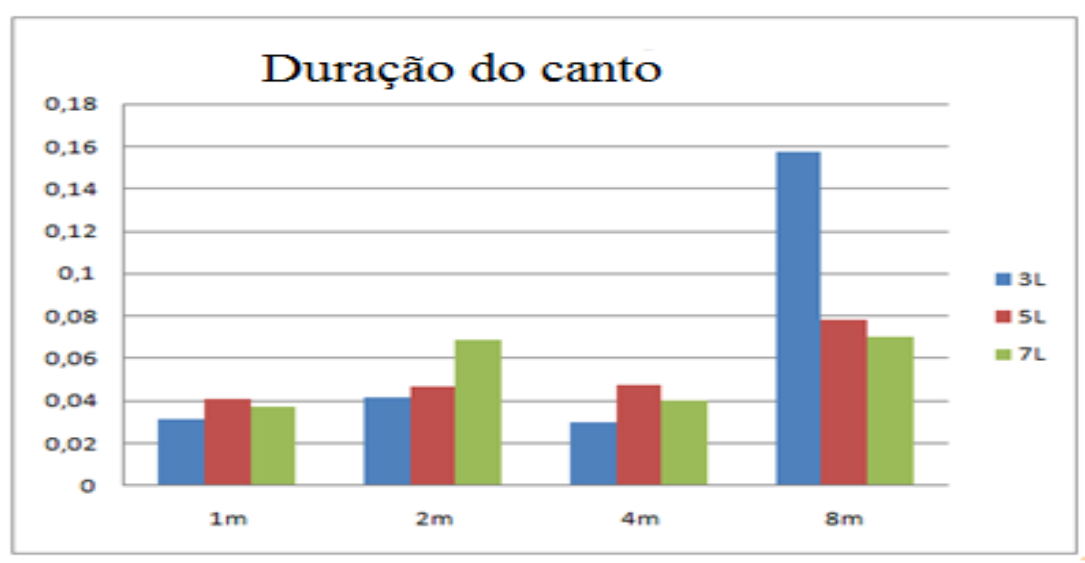

Figura 02. Pico de amplitude $(\mathrm{dB})$ dos cantos de Leptodactylus troglodytes.

A frequiência dominante apresentou muita variação entre as distâncias e também nos diferentes volumes de recipientes utilizados. A maior frequiência dominante obtida no recipiente de cinco litros e aos quatro metros se mostrou com o maior valor. Já o recipiente de 3 litros mostrou tendência a diminuir o valor da freqüência dominante ao longo da transmissão.

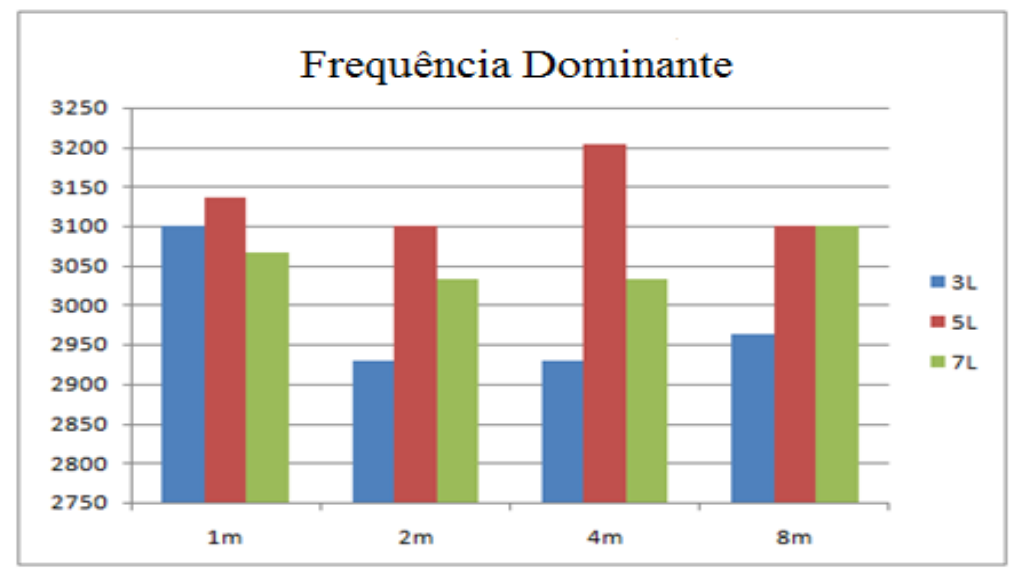

Figura 03. Frequência dominante $(\mathrm{Hz})$ dos cantos analisados. 
No recipiente de 3 litros, a distâncias de $1 \mathrm{~m}, 2 \mathrm{~m}$ e $4 \mathrm{~m}$ houve a menor variação, ou seja, uma maior fidelidade deste parâmetro temporal, este é um aspecto importante para a propagação do canto, pois as características deste se mantêm e o sinal pode ser interpretado pelo receptor. Por outro lado, a 8 metros, neste recipiente (3L) a duração do canto se mostrou muito mais alta. Esse resultado pode ser um artefato criado durante o experimento, ou representar uma adaptação para cantos emitidos em câmaras destas dimensões.

A intensidade do canto é um parâmetro que sofre com as pressões ambientais, podendo ter excesso de atenuação, já que a atenuação do som está presente com ou sem interferência de obstáculos. Conforme as distâncias aumentaram, a intensidade dos cantos diminui. No entanto, as fêmeas preferem cantos com altas intensidades (Gerhardt\& Huber, 2002). Este parâmetro se mostrou eficiente no recipiente de três litros e a $1 \mathrm{~m}$ de distância. A partir de $2 \mathrm{~m}$, o recipiente de $5 \mathrm{~L}$ pareceu manter a intensidade do som com maior alcance. Entretanto, as diferenças não parecem ser significativas e há necessidade de um teste estatístico para certificação.

A frequiência dominante apresentou variações conforme as distâncias onde os cantos foram gravados. Tivemos frequências mais baixas no recipiente de três litros, nas distâncias de dois e quatro metros. Frequências baixas são mais vantajosas, pois sons emitidos em baixa frequência sofrem menos atenuação (Wiley\&Richards,1978).

Além disso, podem ser mais atrativas para as fêmeas, pois estão relacionadas ao tamanho corporal do macho.(Gerhardt\& Huber, 2002).

\section{CONSIDERAÇÕES FINAIS}

A transmissão dos sinais acústicos pode sofrer alterações de acordo com o ambiente e comprometer a interpretação do receptor, dessa forma o canto de anuros precisam ser modulados. Em anfíbios da espécie Leptodactylus trolgodytes a qualidade da transmissão do sinal acústico pode sofrer interferências do sítio de vocalização. De acordo com os resultados, a qualidade do sinal transmitido em termos de fidelidade foi maior quando foram reproduzidas nos recipientes de três litros. Mais experimentos, inclusive medias em campo, poderiam mostrar se as câmaras do solo onde vocalizam esses animais estariam mais próximas a esse volume.

\section{REFERÊNCIAS}

DUELLMAN, W. E., \&TRUEB, L. 1985.Biology of Amphibians. McGraw-Hill, New

York. $670 \mathrm{p}$.

GERHARD, H. C., \& HUBER, F.2002. Acoustic Communication in Insects and

Anurans. University of Chicago Press, Chicago.

HEYER, W. R \& JUNCÁ, F.A. Primeiro registro de Leptodactyluscaatingae (Amphibia, Anura, Leptodactylidae) para o estado do Ceará, Brasil: 2003. Boletim do Museu Paraense Emílio Goeldi. Ciências Naturais 7(2): 153-156.

JUNCÁ, F. A., FUNCH, L. \& ROCHA, W. (Org.). Biodiversidade e Conservação da

Chapada Diamantina - Série Biodiversidade. 1 ed. Distrito Federal -

Brasília, Ministério do Meio Ambiente, v. 13, 411 p. 
POMBAL JR, J.P \& HADDAD, C. F.B. Estratégias e modos reprodutivos de anuros (Amphibia) em uma poça permanente na Serra de Paranapiacaba, Sudeste do Brasil. São Paulo: 2005. 13p.

RYAN, M. J. \&KIME, N. M. 2003. Selection on long distance signals. In: Springer handbook of auditory research: acoustic communication (Simmons A, Fay R. R., Popper A, eds). Berlin: Springer Verlag, 225-274.

RYAN, M. J. 1988. Energy, calling, and selection. American Zoologist, 28:885-898.

Schwartz, J. J. \& Gerhardt, H. C. 1989. Spatially mediated release from auditory masking in an anuran amphibian. J. Comp. Physiol. A, 166: 37-41.

SIMMONS, A. M. 2003. Perspectives and Progress in Animal Acoustic Communication. IN: Acoustic communication / editors, Andrea Megela Simmons, Arthur N. Popper, RichardR. Fay. Springer-Verlag New York, USA, 404 p. WILEY, R. H., \& RICHARDS, D. G. 1978. Physical constraints on acousti communication in theatmosphere: implications for the evolution of animal vocalizations. Behavioral 